\title{
The Relationship Among Parenting Practice Creativity and Parents Mental Health With Intelligence Quotient and Behavioral Disorder of 7-8 Years Old Children in Qaemshahr City
}

\author{
Nastaran Hasanli* \\ Faculty of Social Science and Psychology, Baku State University, Baku, Azerbaijan
}

\begin{abstract}
Background: The aim of this study was the survey of the relationship of parenting practice, creativity and parent's mental health with intelligence quotient and behavioral disorder of 7-8 years old children in Qaemshahr city.

Methods: In this cross-sectional descriptive-analytical study. The statistical population consisted of seven and eight years old children in Qaemshahr city in 2017. Three hundred children among them selected with stratified random sampling. Data gathered by Baumrind parenting practices questionnaire, Thurstone and Mellinger creativity questionnaire, Derogatis mental health, Wechsler intelligence scale for children and Rutter children's behavioral disorder. Data analysis executed by one-way ANOVA test and Pearson correlation with SPSS 22.

Results: The results showed that there is no significant difference between behavioral disorder rate of boys \& girls $(P<0.05)$. Also, there is the significant relationship among parenting practices with intelligence quotient and children behavioral disorder $(P<0.05)$, while there was no significant relationship between intelligence quotient and children's behavioral disorder with creativity $(P<0.05)$. Moreover, there was a significant relationship between mental health with behavioral disorder among children $(P<0.05)$, however, there was no significant relationship with intelligence quotient $(P<0.05)$.

Conclusion: According to research results we can conclude that welfare and educational equipment's by short-term, medium-term and long-term planning may enhance health and mental comfort among families with their children's behavioral disorders.

Keywords: Parenting practices; Creativity; Mental health; Intelligence quotient; Behavioral disorder
\end{abstract}

*Correspondence to Nastaran Hasanli, Baku University, Baku, Azerbaijan Tel/Fax: +989335123198; Email:

nastaranhassanali7@gmail. com

Published online 20 March 2019

Citation: Hasanli N. The relationship among parenting practice creativity and parents mental health with intelligence quotient and behavioral disorder of 7-8 years old children in Qaemshahr city. Int Clin Neurosci J. 2019;6(1):22-27. doi:10.15171/icnj.2019.05.

\section{Introduction}

Children as vulnerable age groups have different psychological problems. Development active process and controlling child's environmental situations by adults effect on children's vulnerability. ${ }^{1}$ Although extending equipment has increased people lifetime, different problems in societies, especially in developing countries have resulted in children and youths problems. ${ }^{2,3}$ Behavioral and emotional problems created in the children's development process. Behavioral problem refers to behavior without low intelligence quotient, high mental and behavioral equilibrium, with severity, repetition, and constancy. Such behavior disturbs in the child's educational and behavioral performance and may result in helplessness and efficiency rate declining. There are rejected by the others directly or indirectly. ${ }^{5}$ Children with behavioral disorders create different individual - social problems for families, schools and societies. ${ }^{6}$
Of course, effective and behavioral disorders disturb children ability for social educational and emotional performance. ${ }^{7}$ Some problems such as attention and hyperactivity, conduct disorder, generalized anxiety, depression, and fear maybe appeared in some states like beating, screaming, sabotaging, threatening, school's escaping and academic failure, these states may be known as behavioral problems if the be continuous and self-excited. ${ }^{8}$ The family is the first factor affecting on person's personality development. Parents affect their children genetically and acquire. ${ }^{9}$ The family is effective on a child's acquaintance with social life and culture. They may solve problems among self and their children by parenting practices learning. ${ }^{10}$ Family environment is one of the most effective factors in children's personality development. Human acquires kingdom feeling, security and learning the ability in the family environment and learns necessary social skills by communicating between

(C) 2019 The Author(s). This is an open access article distributed under the terms of the Creative Commons Attribution License (http:// creativecommons.org/licenses/by/4.0/), which permits unrestricted use, distribution, and reproduction in any medium, provided the original work is properly cited. 
his/her parents and also playing with his/her congener, ${ }^{11}$ adequate equipment's with sufficient stimulus is necessary to learn. Family structure and child's role effect on his/ her personality development. Although, child's genetic features are active on his/her personality development, however, these features in the proper environment may effect on his/her personality development, ${ }^{12,13}$ the family is very active on members behavior. Family conditions such as, economic situation, person's relationships, training condition, familial values, effective and moral conditions, rigor, security and family constancy effect on children's psychological features development. Also addicting one stable of behavioral disorders in childhood is related to some psychiatry disorders such as antisocial behavior at future such as substance use disorder. ${ }^{14}$

According to pathology attitude, behavioral and mental problems among children may have resulted from different factors. With regarding the relationship between family and child, family as one primary system may be effective on children's mental and behavioral problems. Studies show that positive relationship between parents with children and giving fit freedom may result in little behavioral problems, ${ }^{15}$ studies show that parents' intimacy demands may result in cooperation's children and also when children obey eagerly, their parents world kind at future. In contrast, parents with high discipline may affect their children's rebellion. Its reason is that children's misbehavior is stressful for parents. Thus, they increase punishment using that may result in children's more rebellion..$^{10,16,17}$

Feraghati et al found that there is a significant relationship between logical authority styles with children's intelligence and the other two parenting styles (perfect liberalization style and autocratic liberalization style) could not explain intelligence changes. This finding may indicate that parenting styles are one of the critical factors for children's intelligence. ${ }^{18}$ Maktabi et al found that there is no significant relationship among perfect liberalization style and logical authority with a behavioral disorder, but there is a significant relationship between autocratic liberalization style and behavioral disorder. ${ }^{19}$ Thus, parents training styles are essential for children's mental health, because health relationship may result in better identification of children's needs. ${ }^{20}$ Abbasi and Ghasemi found that there is a significant relationship between student's intelligence and creativity. ${ }^{21}$ Maleki showed that there is a positive \& significant relationship between students mental health with emotional intelligence components. ${ }^{22}$ According to executed studies, mother's mental health may predict student's behavioral disorder. ${ }^{23,24}$ Usta and Akkanat found that there is a significant relationship between creativity and attitude toward science in the classroom, of course, student's creativity was low in this field. ${ }^{25}$ Walker et al found that students who have participated in preschool classes have a favorable social adjustment. The child with disorder or disability may be a stressful factor for family and effect on all dimensions of the family. ${ }^{26,27}$ Parents and children effect on each other personally, developmentally and behaviorally. ${ }^{28}$ Behavioral disorders are the most prevalent problems of children their effect on the mental and social functions of all family members. Mother with the most interaction with the child may be more vulnerable. ${ }^{29}$ Therefore study's importance of effective factors on children's behavioral problems becomes clear. Also, little studies have been executed in this field, thus executing such studies to determine children's behavioral problems seem necessary. Therefore the aim of this study was the survey of the relationship of parenting practice, creativity and parent's mental health with intelligence quotient and behavioral disorder of 7-8 years old children in Qaemshahr city.

\section{Methods}

In this cross-sectional descriptive-analytical study, the statistical population consisted of 7 and 8 years old children in Qaemshahr city in 2017 (1355 persons). Based on the Cochran formula, 300 children among them selected with stratified random sampling. In this way, Qaemshahr city divided into 3 regions, and the schools located in each of these regions formed a class, and the sample size in each class was random and proportional to the population of that class. The number of $1,2 \& 3$ regions were determined 75, 128 \& 97 persons orderly. Data collection measurements were Baumrind parenting practices questionnaire, Thurstone and Mellinger creativity questionnaire, Derogatis mental health, Wechsler intelligence scale for children and Rutter children's behavioral disorder. Data analysis executed by one-way ANOVA test and Pearson correlation with SPSS version 22 .

\section{Mental Health Questionnaire (SCL-90)}

It has been introduced by Derogatis et al in 1973 and the revised form prepared in $1976 .{ }^{26}$ Ninety items of this test consist of different dimensions, physical complaint, obsession, sensitivity in a mutual relationship, depression, anxiety, aggression, morbid fear, paranoid thoughts, and psychosis. This test scoring and interpretation calculated at 5-degree scale (from never until extremely based on 3 indicators of the total coefficient of morbid symptoms, uneasy coefficient criterion, and morbid symptoms sum). The higher score indicates morbid symptoms. This questionnaire was completed by the child's mother (subject).

The validity and reliability of the questionnaire has been successfully evaluated by Modabernia et al. ${ }^{30}$

\section{Child Behavioral Disorders Questionnaire}

Rutter has designed this tool with 30 questions for 7-13 years old children that measures hyperactivity, aggression, anxiety, depression, social maladjustment, antisocial 
behaviors, attention disorder and distraction by parent's attitude. ${ }^{31}$ Responding time to this questionnaire is 20 minutes. Scoring scale is between $0-2$. Therefore, the score of each subject varies from 0 to 60 . Rutter reported retest reliability and internal reliability at one pretest and posttest study acceptable. Yousefi reported this questionnaire reliability by retest method 0.90 . This questionnaire was completed by the child's mother (subject). ${ }^{32}$

\section{Parenting Style Questionnaire}

This questionnaire was designed by Baumrind in 1972 to study parenting practices. This questionnaire consists of 30 questions that measure parenting practices in 3 dimensions (10 items by perfect liberalization style, 10 items by autocratic liberalization style and the other ten questions by logical authority). The subject should identify his/her opinion by 5-degree scale (disagree completely, disagree, almost agree and agree). Validity coefficients for absolute liberalization style, autocratic liberalization style, and logical authority style have been reported $0.81,0.86$ and 0.78 , respectively. ${ }^{33}$ Farahini et al reported Cronbach's alpha for absolute liberalization, autocratic liberalization and logical authority styles 0.76 , 0.72 and 0.74 , respectively. ${ }^{34}$ This questionnaire completed by subject's mother (child).

\section{Creativity Questionnaire (CREE)}

This questionnaire was designed by Thurstone \& Mellinger that identifies persons' potential creativity. This test consists of 145 questions. Each question is about the subject (yes/no). Person's score is equal to the number times that his/her responses coordinated with the creative person's responses. This question is a very suitable tool to predict creativity correctly. ${ }^{35}$ This questionnaire completed by the child's mother (subject).

\section{Wechsler Intelligence Scale for Children (WISC)}

Wechsler children intelligence main scale consists of 12 subscales, general information, calculation, similarities, words, numerical memory, total understanding, pictures completing, pictures, pieces combining, mazes, cubes designing and cryptography. ${ }^{36}$ Subscales organized at 2 scales (verbal and practical). Three scores of verbal intelligence quotient, practical intelligence quotient, and total intelligence quotient are related to this scale. At revised Wechsler Intelligence Scale for Children (Wechsler, 1974) 12 subscales and 3 intelligence quotients did not change. However, the age range changed from 5-15 years into 6-16 years old. ${ }^{37}$ Sadeghi and colleagues reported Cronbach's alpha of verbal intelligence, practical intelligence and total intelligence $0.88,0.80$ and 0.91 , respectively. ${ }^{38}$ The questionnaire was about the child, and the psychologist completed the items of the questionnaire.

\section{Results}

In this study, $2 \%$ of respondents were 5 years old, $35 \%$ were 6 years old, $38 \%$ were 7 years old, and $25 \%$ were 8 years old. Also, $57 \%$ were the boys, and $43 \%$ were the girl. $86 \%$ from mothers were householders $6 \%$ were teachers, $4 \%$ was the clerk, $1 \%$ was the physician, and $3 \%$ were self-employed. $94 \%$ of fathers had self-employment, $15 \%$ were clerks, $3 \%$ were teachers, $1 \%$ was the physician, $2 \%$ were military, $3 \%$ retired and $2 \%$ were the manual worker. Descriptive information about research variables consists of mean, standard deviation, maximum and minimum have been shown in Table 1.

According to Table 2, behavioral disorder score mean for absolute liberalization style is the least among parenting style and the most score of the behavioral disorder is related to autocratic liberalization style. Oneway variance analysis test (ANOVA) showed that there is a significant difference between parenting practices and children's behavioral disorder score $(P<0.05)$.

Based on Table 3 , the mean score of all intelligence scales (verbal, practical and total score of intelligence) for absolute liberalization style is the most score among the other parenting styles. Moreover, the least intelligence quotient has seen for autocratic liberalization style, according to narrow analysis test results, differences among verbal intelligence $(\mathrm{f}=5.631, P=0.004)$ practical intelligence $(f=5.653, P=0.004)$ and total score of intelligence $(\mathrm{f}=3.883, P=0.022)$ styles are significant statistically.

The Pearson correlation coefficient test was used to examine the relationship between the level of creativity in the family and mental health with the mean score of children's behavioral disorder (Table 4). Person correlation coefficient test showed a negative correlation between creativity and behavioral disorder, but this relationship was not significant statistically $(P>0.05)$. Also, there was a positive and significant correlation between mental health and behavioral disorder $(P<0.05)$.

Person correlational coefficient test results showed that there is a positive correlation between creativity rate in family and children's intelligence coefficient. However,

Table 1. Descriptive Information of the Studied Variables

\begin{tabular}{lllll}
\hline Variables & Mean & SD & Maximum & Minimum \\
\hline Mental health & 74.23 & 58.65 & 1 & 215 \\
Behavioral disorder & 8.54 & 5.26 & 0 & 19 \\
Creativity & 81 & 18.64 & 42 & 120 \\
Parenting style & 34 & 12.26 & 9 & 96 \\
Intelligence quotient & 106.43 & 15.75 & 47 & 135 \\
\hline
\end{tabular}

Table 2. Mean Comparison of Behavioral Disorder Score Based on Parenting Practices

\begin{tabular}{lllll}
\hline Parenting style & Frequency & Mean \pm SD & F & P Value \\
\hline Absolute liberalization & 9 & $6.33 \pm 0.5$ & & \\
Autocratic liberalization & 63 & $8.85 \pm 4.9$ & 3.382 & 0.036 \\
Logical authority & 189 & $8.5 \pm 5.5$ & & \\
\hline
\end{tabular}


Table 3. Mean Comparison of Intelligence Score Based on Parenting Styles

\begin{tabular}{|c|c|c|c|c|}
\hline Parenting style & Intelligence Scale & Frequency & Mean & SD \\
\hline \multirow{3}{*}{ Absolute liberalization } & Verbal intelligence & 9 & 122.33 & 11.948 \\
\hline & Practical intelligence & 9 & 1.7 .33 & 12.619 \\
\hline & Total score of intelligence & 9 & 116.33 & 11.79 \\
\hline \multirow{3}{*}{ Autocratic liberalization } & Verbal intelligence & 75 & 103.72 & 20.49 \\
\hline & Practical intelligence & 75 & 99.28 & 20.568 \\
\hline & Total score of intelligence & 75 & 105 & 13.99 \\
\hline \multirow{3}{*}{ Logical authority } & Verbal intelligence & 198 & 109.73 & 17.494 \\
\hline & Practical intelligence & 195 & 105.58 & 10.716 \\
\hline & Total score of intelligence & 198 & 108.42 & 12.467 \\
\hline
\end{tabular}

this relationship is not significant statistically $(P>0.05)$. Also, findings showed that there is a reversed correlation between mental health and intelligence. This relationship was not significant statistically $(P>0.05)$ (Table 5).

\section{Discussion}

The present study showed the relationship among parenting practice, creativity, creativity and mental health with the behavioral disorder and intelligence quotient of 7-8 years old children in Qaemshahr city. We found that there is a significant difference between the scoring rate of children's behavioral disorder and intelligence quotient in parenting practices. In other words, parenting practices may predict children's intelligence quotient and behavioral disorder. These findings are consistent with Tarkeshdooz and Farokhzad, ${ }^{39}$ Feraghati et al, ${ }^{18}$ Maktabi et al, ${ }^{19}$ Razavi et $\mathrm{a}^{40}$ and Gillberg. ${ }^{28}$ Some factors such as difference in used instrument kind, data collecting situations, subject's diversity or family, cultural, mental \& social situations may effect on significance these styles upon specific behavior. Parents with using punishment may create severe hostility feeling in their children because of executing high limitation. They may result in the child's anger. Two

Table 4. Correlation Test of the Creativity Rate in Family \& Mental Health With Children's Behavioral Disorder

\begin{tabular}{llll}
\hline Variables & R & Frequency & $\boldsymbol{P}$ value \\
\hline Creativity & -0.014 & 246 & 0.867 \\
Mental health & 0.344 & 222 & 0.000 \\
\hline
\end{tabular}

Table 5. Correlation Test of the Creativity rate in the Family With Children's Intelligence Score

\begin{tabular}{lcll}
\hline Variable & R & Frequency & $\boldsymbol{P}$ value \\
\hline \multicolumn{4}{c}{ Creativity } \\
\hline Verbal intelligence & 0.044 & 282 & 0.615 \\
Practical intelligence & 0.090 & 279 & 0.305 \\
Total score of intelligence & 0.050 & 282 & 0.402 \\
\hline \multicolumn{4}{c}{ Mental Health } \\
\hline Verbal intelligence & -0.123 & 246 & 0.054 \\
Practical intelligence & -0.004 & 243 & 0.952 \\
Total score of intelligence & -0.065 & 246 & 0.309 \\
\hline
\end{tabular}

factors, parent's hostility, and children's freedom limitation may create severe hostility in these children. Some studies have indicated that parents of children with conduct disorder usually are limited, grueling and expected. They do not pay attention to their children's needs. They limit their children and control them severely and have little verbal contact and believe that their children should be mere submissive. ${ }^{41}$ We can state that autocratic liberalization style and absolute liberalization style are inefficient training styles that may result in different behavioral and affective problems among children. In families with logical authority, family members can be speaking in a friendly way, and other members listen to their sayings, this will provide self-esteem in each family. Hence, it can expect that children with a logical authority parenting style have higher mental health and intelligence quotient. They know their environment well and created obligation feeling. Also, they may express their abilities and merits for solving problems; they learn that different experiences are valuable, therefore challenging feeling is replaced by behavioral disorders. The other findings of the study showed that creativity rate increasing might improve children's intelligence quotient, also increasing creativity rate may decrease the child's behavioral disorders rate. Of course, relationships between creativity with the behavioral disorder and children's intelligence quotient were not significant statistically. These findings are consistent with Batey and colleagues, ${ }^{42}$ Gute et al, ${ }^{43}$ Hocevar. ${ }^{44}$ The studies showed that genetic factors are effective in persons' creativity. Being creative of parents may be the underline of children's creativity creating because being familiar with the creative person's behaviors effect on the way of encountering with creative children. Problem-solving, creativity is at the highest level of human cognitive activity, and the main aim of all educational units is creating problem-solving and creativity among children, regarding persons' creative abilities, providing right situations and developing and extending ambiguity, contradiction, and no external control may improve creativity. ${ }^{45}$ However, results are not consistent with Abbasi et $\mathrm{al},{ }^{21}$ Usta and Akkanat, ${ }^{25}$ Winner ${ }^{46}$ research. Intimacy, acceptance, sense of humor, self-assertion situation and satisfaction may improve children's creativity. This issue 
may effect on present study findings and lead to different results from what obtained in previous studies. Also being different of used questionnaire, different social and cultural situations may effect on results. Moreover, the present study results illustrated that there is a significant relationship between the parent's mental health and children's behavioral disorder but didn't have a significant relationship with intelligence quotient. These findings are consistent with Mohammad Esmaeil and Mousavi, ${ }^{23}$ Leinonen et $\mathrm{al}_{,}{ }^{47} \mathrm{Green}^{48}$ and Beardslee et $\mathrm{al}^{49}$ studies. Parental communications may have a great impact on emotional and mental health development of the child, so whatever, the family has healthier and more sincere beliefs, the healthier and more efficient children will deliver to the community. Children are one of the groups that are prone to behavioral problems, and one of the causes of childhood behavioral disorders is related to their interaction with parents, especially patient parents. ${ }^{23}$ Since children's communication is almost with housewife's mother, especially in Iran, children are limited to their social communication, and most children's behavioral models are created based on interaction with family especially the mother. Parent's behavioral disorders may result in morbid models creating by the child. Report of humanistic services policy school in Washington University indicated that week mental health or high aggression by parents might result in severe behavioralaffective problems in school children (5 more than parents without these problems). ${ }^{50}$

\section{Conclusion}

According to the results of the current study, we can state that by planning and providing the necessary welfare and educational facilities for children with behavioral problems, while preventing behavioral problems in these children, it can be increased their families health and mental comfort. Also, educational programs provided for families and teachers, in which the content of these training includes the opportunity to express feelings, verbal skills, narrating (storytelling), exhibition and other factors associated with increasing verbal intelligence and children's intelligence quotient.

\section{Conflict of Interest Disclosures}

The authors declare that they have no conflict of interests.

\section{Ethical Statement}

All ethical principles were considered in this article. The participants were informed about the purpose of the research and its implementation stages and signed the informed consent; they were also assured about the confidentiality of their information; Moreover, They were allowed to leave the study whenever they wish, and if desired, the results of the research would be available to them.

\section{References}

1. Heydari J, Azimi H, Mahmoudi G, Mohammadpour RA. Prevalence of behavior-emotional disorders and its associated factors among the primary school students of Sari township in
2006. Journal of Mazandaran University of Medical Sciences. 2007;16(56):91-100.

2. Rezaei T, Yazdi-Ravandi S, Ghaleiha A, Seif Rabiei MA. Depression among medical students of Hamadan University of Medical Sciences in 2014: The Role of demographic variables. Pajouhan Scientific Journal. 2015;13(4):1-8.

3. Azami E, Hajsadeghi Z, Yazdi-Ravandi S. The comparative study of effectiveness of training communication and emotional skills on parenting stress of mothers with autism children. Zanko Journal of Medical Sciences. 2017;18(56):111.

4. Sajedi Z, Zarabian K, Sadeghian E. Prevalence Behavior Disorders in 3 to 6 Years' Children in Hamadan City. Scientific Journal of Hamadan Nursing \& Midwifery Faculty. 2010;18(1):11-21. [Persian].

5. Astill RG, Van der Heijden KB, Van Ijzendoorn MH, Van Someren EJ. Sleep, cognition, and behavioral problems in school-age children: a century of research meta-analyzed. Psychol Bull. 2012;138(6):1109-38. doi: 10.1037/a0028204.

6. Sarihi N, Pournesaei GS, Nikakhlagh M. [Effectiveness of group play therapy on behavior problems in preschool children]. Journal of Analytical-Cognitive Psychology. 2015;6(23):35-41. [Persian].

7. Saberi H. Epidemiology of emotional and behavioral disorders in elementary children. Thought and Behavior. 2008;2(8):1934.

8. Hallahan DP, Kauffman JM, Pullen PC. Exceptional learners: An introduction to special education. Allyn and Bacon Boston; 1997.

9. Hossieni Garavandi A, Yazdi-Ravandi S, Hajsadeghi Z. Role of androgenic trends, parenting practices, and negative attributional style on spiritual coping among students of Islamic Azad University of Ahvaz, Iran, 2016. Journal of Community Health. 2017;11(1):30-9. doi: 10.22123/ chj.2018.85436.

10. Steinberg L, Darling N. Parenting style as context: An integrative model. Psychol Bull. 1993;113(3):487-96. doi: 10.1037/0033-2909.113.3.487.

11. Kurdek LA, Fine MA. Family acceptance and family control as predictors of adjustment in young adolescents: linear, curvilinear, or interactive effects? Child Dev. 1994;65(4):113746.

12. Keenan T, Evans S, Crowley K. An introduction to child development. 3rd ed. London: Sage Publications; 2016.

13. Larsen RJ, Buss DM, Wismeijer A, Song J, van den Berg SM. Personality psychology: Domains of knowledge about human nature. New York: McGraw Hill Education; 2017.

14. Zemp M, Milek A, Cummings EM, Cina A, Bodenmann G. How couple-and parenting-focused programs affect child behavioral problems: A randomized controlled trial. J Child Fam Stud. 2016;25(3):798-810. doi: 10.1007/s10826-0150260-1.

15. O'Byrne KK, Haddock CK, Poston WS. Parenting style and adolescent smoking. J Adolesc Health. 2002;30(6):418-25. doi: 10.1016/S1054-139X(02)00370-1.

16. Querido JG, Warner TD, Eyberg SM. Parenting styles and child behavior in African American families of preschool children. J Clin Child Adolesc Psychol. 2002;31(2):272-7. doi: 10.1207/ s15374424jccp3102_12.

17. Huang CY, Costeines J, Ayala C, Kaufman JS. Parenting Stress, Social Support, and Depression for Ethnic Minority Adolescent Mothers: Impact on Child Development. J Child Fam Stud. 2014;23(2):255-62. doi: 10.1007/s10826-013-9807-1.

18. Feraghati $M$, Eskandari $H$, Azizi Rad Z. Investigating the relationship between parenting practices and intelligence in kindergartens of Iran University of Medical Sciences. Tehran: 
International Conference on Humanities, Psychology and Social Sciences; 2015.

19. Maktabi G, Nayemavi M, Rahimi H, Tofanizadeh K. The relationship between parenting practices and behavioral disorders in preschool children in Shadegan. Tehran: National Conference on Psychology of Educational and Social Sciences; 2015.

20. Boe T, Sivertsen B, Heiervang E, Goodman R, Lundervold AJ, Hysing $M$. Socioeconomic status and child mental health: the role of parental emotional well-being and parenting practices. J Abnorm Child Psychol. 2014;42(5):705-15. doi: 10.1007/ s10802-013-9818-9.

21. Abbasi H, Ghasemi P. Investigating the relationship between intelligence and creativity of third grade students in Nourabad city. Tehran: International Conference on Humanities and Behavioral Studies; 2014

22. Maleki H. The Relationship between Emotional Intelligence and Creativity among High School Students. Quarterly Journal of Research in Educational Systems. 2016;10(33):190209. [Persian].

23. Mohammad Esmaeil E, Sadat Mousavi H. An investigation on mental health of mothers with behaviorally Disordered children. Journal of Exceptional Children. 2003;3(2):105-16.

24. Hastings RP. Child behaviour problems and partner mental health as correlates of stress in mothers and fathers of children with autism. J Intellect Disabil Res. 2003;47(Pt 4-5):231-7.

25. Usta E, Akkanat C. Investigating Scientific Creativity Level of Seventh Grade Students. Procedia Soc Behav Sci. 2015;191:1408-15. doi: 10.1016/j.sbspro.2015.04.643.

26. Walker AM, Koestner R, Hum A. Personality correlates of depressive style in autobiographies of creative achievers. J Creat Behav. 1995;29(2):75-94. doi: 10.1002/j.21626057.1995.tb00738.x.

27. Smolak L. Child characteristics in marital speech. J Child Lang. 1987;14:481-4.

28. Gillberg C. Deficits in attention, motor control, and perception: a brief review. Arch Dis Child. 2003;88(10):904-10.

29. Derogatis LR, Rickels K, Rock AF. The SCL-90 and the MMPI: a step in the validation of a new self-report scale. Br J Psychiatry. 1976;128:280-9.

30. Modabernia MJ, Shojaie Tehranie H, Falahi M, Faghirpour M. Normalizing SCL-90-R inventory in Guilan high-school students. Journal of Guilan University of Medical Sciences. 2010;19(75):58-65.

31. Rutter M. A children's behaviour questionnaire for completion by teachers: preliminary findings. J Child Psychol Psychiatry. 1967;8(1):1-11.

32. Yousefi F. Standardization of Rutter's Questionnaire to Study the Behavioral and Emotional Problems of Elementary School Students in Shiraz. Journal of Social Sciences and Human Sciences of Shiraz University. 1998;13(2):171-94. [Persian].

33. Buri JR. Parental authority questionnaire. Journal of personality assessment. 1991:57(1):110-9.

34. Farahini N, Afrooz GH, Rasoulzadeh-Tabatabaei K. The relationship between parenting styles, shyness and creativity in the gifted. Journal of School Psychology. 2014;2(4): 137 53.

35. Thurstone TG, Mellinger J. CREE questionnaire. Chicago: Industrial Relations Center; 1957.

36. Wechsler D. Wechsler intelligence scale for children. San Antonio: Psychological Corporation; 1949.

37. Wechsler D. Wechsler intelligence scale for children-WISCIV. San Antonio: Psychological Corporation; 2003.

38. Sadeghi A, Rabiee M, Abedi MR. Validation and reliability of the Wechsler Intelligence Scale for Children-IV. Scientific Journal Management System. 2011;7(28):377-86.

39. Tarkeshdooz S, Farokhzad P. The relationship between children behavioral disorders with parenting styles and attachment styles. Community Health. 2017;4(2):118-26.

40. Razavi A, Mahmoudi M, Rahimi M. The relationship between satisfaction couples and parenting styles parents of elementary school children with behavioral problems in Arsanjan. Quarterly Journal of Family and Research. 2008;2(4):73-90.

41. Jonbozorgi M, Nouri N, Hosseini K. The study of relationship building family values and self-esteem of students. Sociology of the family. 2010;19:53-64.

42. Batey M, Chamorro-Premuzic T, Furnham A. Intelligence and personality as predictors of divergent thinking: The role of general, fluid and crystallised intelligence. Think Skills Creat. 2009;4(1):60-9. doi: 10.1016/j.tsc.2009.01.002.

43. Gute G, Gute DS, Nakamura J, Csikszentmihalyi M. The early lives of highly creative persons: The influence of the complex family. Creat Res J. 2008;20(4):343-57. doi: 10.1080/10400410802391207.

44. Hocevar D. Intelligence, divergent thinking, and creativity. Intelligence. 1980;4(1):25-40. doi: 10.1016/01602896(80)90004-5.

45. Eslami Nasab A. Compatibility Psychology. Tehran: Bonyad; 2010. [Persian].

46. Winner E. The origins and ends of giftedness. Am Psychol. 2000;55(1):159-69.

47. Leinonen JA, Solantaus TS, Punamaki RL. Parental mental health and children's adjustment: the quality of marital interaction and parenting as mediating factors. J Child Psychol Psychiatry. 2003;44(2):227-41.

48. Mok PL, Webb RT, Appleby L, Pedersen CB. Full spectrum of mental disorders linked with childhood residential mobility. Journal of Psychiatric Research. 2016;78(1):57-64.

49. Beardslee WR, Bemporad J, Keller MB, Klerman GL. Children of parents with major affective disorder: a review. Am J Psychiatry. 1983;140(7):825-32. doi: 10.1176/ajp.140.7.825.

50. Annie E. Washington-Kids count data book. Washington: Casey Foundation Center for the Study of Social Policy; 2001. 